\title{
Erratum: Why biotech don't pay dividends-yet
}

Tom Jacobs

Nat. Biotechnol. 21, 1283 (2003)

The title of this article contained a typographical error. The title should have read: "Why biotechs don't pay dividends-yet". Nature Biotechnology regrets the error.

\section{Erratum: New biotech hubs may emerge as industry matures}

\section{Paroma Basu}

Nat. Biotechnol. 21, 1123, 2003

The title of Table 1 incorrectly indicates the presence of data for 48 North American cities or counties. The original article, which appears in the News section of the Bioentrepreneur web portal (http://www.nature.com/bioent), does indeed contain these data. But the version reprinted here displays a truncated version of the table with ten data points: North American cities or counties that rank 1-5 and 43-48 in total annual operating costs for a biomedical research and development facility. Nature Biotechnology regrets the error.

\section{Corrigendum: Invention and commercialization in optical bioimaging}

Daniel L. Farkas

Nat. Biotechnol. 21, 1269-1271, 2003

The URL that appeared on p. 1271 was incorrect. The correct URL is http://www.ptei.org/educational_programs/Planetarium/ planetarium_project.html. 